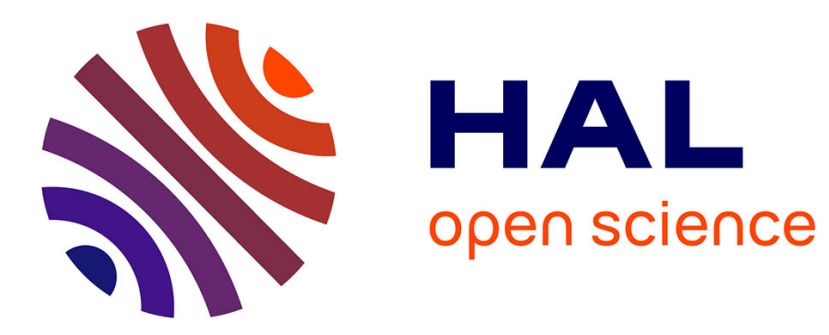

\title{
Viscoelastic properties identification through innovative Image-Based DMTA strategy
}

Rian Seghir, Fabrice Pierron

\section{To cite this version:}

Rian Seghir, Fabrice Pierron. Viscoelastic properties identification through innovative Image-Based DMTA strategy. CFM 2017 - 23ème Congrès Français de Mécanique, Aug 2017, Lille, France. hal03465321

\section{HAL Id: hal-03465321 \\ https://hal.science/hal-03465321}

Submitted on 3 Dec 2021

HAL is a multi-disciplinary open access archive for the deposit and dissemination of scientific research documents, whether they are published or not. The documents may come from teaching and research institutions in France or abroad, or from public or private research centers.
L'archive ouverte pluridisciplinaire HAL, est destinée au dépôt et à la diffusion de documents scientifiques de niveau recherche, publiés ou non, émanant des établissements d'enseignement et de recherche français ou étrangers, des laboratoires publics ou privés. 


\title{
Viscoelastic properties identification through innovative Image-Based DMTA strategy
}

\author{
R. SEGHIR ${ }^{a *}$, F. PIERRON ${ }^{a}$
}

a. Faculty of Engineering and the Environment, University of Southampton

Highfield Campus, SO17 1BJ Southampton, UK

*r.seghir@soton.ac.uk

\section{Résumé :}

L'évaluation fine des propriétés matériaux à haute vitesse de déformation est cruciale pour de nombreuses applications telles que la mise en forme, la résistance au crash ...Il s'agit par ailleurs d'un véritable défi expérimental notamment du fait de la difficulté d'estimer précisément les efforts d'impact en régime transitoire où lorsque le domaine analysé ne se prête plus aux hypothèses de milieu homogène. Nous présentons ici, une stratégie d'identification unique, reposant sur l'utilisation conjointe de chargements ultrasons, d'imagerie visible ultra-rapide, de thermographie infrarouge et de la méthode de grille. Ces derniers permettent l'identification simultanée des propriétés viscoélastiques de matériaux polymères sur une large gamme de vitesse de déformation et de température. La principale originalité repose sur le fait que l'essai est conçu pour produire simultanément une forte hétérogénéité spatiale des conditions de chargement locales, qui, couplée à une stratégie originale de reconstruction expérimentale des champs de contraintes permet une identification plus riche à partir d'un unique essai.

\section{Abstract :}

The identification of the high strain-rate properties of materials is an important topic for many engineering applications such as crash worthiness, blast loading, industrial forming, among others. It is also a very challenging experimental task mainly because of the difficulty in measuring impact loads accurately in regimes where inertia effects are significant as well as in presence of heterogeneous deformation states. We present here an innovative identification strategy, using high power ultrasonic loadings together with both InfraRed Thermography, Ultra-High-Speed Imaging and grid method, able to simultaneously characterize the viscoelastic behaviour of polymer materials over a large loading spectrum. The main originalities lies in the fact that heterogeneous stress fields are experimentally reconstructed through acceleration fields measurement and that contrary to conventional DMA, no frequency or temperature sweep is required since the experiment is designed to simultaneously produce both a heterogeneous strain-rate state (up to $400 \mathrm{~s}^{-1}$ ) and a heterogeneous temperature state (up to the glassy transition point) allowing a local and "spectral" identification.

\section{Mots clefs : Ultra-High Speed, visco-elasticity, PMMA, Infrared Thermogra- phy, Identification}




\section{Introduction}

The identification of the high strain-rate properties of materials is a very important topic for many engineering applications like crash, blast, forming among others. It is also a very challenging experimental task mainly because of the difficulty in measuring impact loads accurately in regimes where inertia effects are significant (transient and elastic regimes) as well as in presence of heterogeneous deformation states. Especially, the most popular technique used to obtain material parameters at high strain-rates, i.e. the Split Hopkinson Bar, does not overcome such limits. From a more general point of view, fully characterising material, even at quasi-static rate, still required nowadays a trying series of elementary tests mainly due to our incapacity to extract the stress distribution under complex experimental conditions. A recent alternative is to take advantage of the acceleration information using it as an image-embedded load cell [1]. Even more recently, a very interesting article was published in [2] where a sawbone specimen was submitted to longitudinal vibrational excitation in the ultrasonic range, and its response measured by DIC and IR thermography. The objective of the present work is to show that both approaches can be combined to extract storage modulus and damping properties from these images. Such technique go further than standard DMT analysis, in the sense that deformations, stresses and temperatures are extracted locally to constitute an impressive experimental database ready for identification.

\section{Test principle}

The concept of this work, recently introduced in [3, 4], consists in producing within a visco-elastic sample, both an heterogeneous deformation-rate state and an heterogeneous temperature state. This is achieved loading the sample cyclically at high frequency using a reasonably high loading amplitude. In these conditions, and if the sample is designed to be resonant ( $1^{s t}$ longitudinal mode) at the loading frequency, it undergoes an harmonic deformation state where both the strain and the strain-rate are null at sample extremities (free and fixed edges - see figure 1) and are maximum within its centre. In parallel, the sample is self-heated cycle after cycle due to the visco-elastic dissipation. This dissipation contributes to gradually heat-up the centre of the sample while the edges remains almost at room temperature. In other words, the test produces, room temperature quasi-static uniaxial tests close to sample edges and high deformation rate uniaxial tests at varying temperature within the centre. Material points located in between provide a range of experimental conditions. The challenge is to take profit of all this heterogeneity. In the present case, each material section is treated as an "independent sample" and the local stress state is computed from the dynamic equilibrium. Indeed, one can easily demonstrate from the equilibrium of a free-standing homogeneous flat sample loaded along its longitudinal axis that:

$$
{\overline{\sigma_{y y}}}^{x}(y, t)=\rho y \overline{a_{y}}(y, t)
$$

where ${\overline{\sigma_{y y}}}^{x}$ is the averaged longitudinal Cauchy-stress over the section $y$ and $\overline{a_{y}}$ is the averaged acceleration between the free edge and the section $y$.

\section{Experimental setup and material}

The experimental setup consists in four main parts as shown in figure 1. (1) An high power Ultrasonic transducer which allows cyclically deforming the sample at $20 \mathrm{kHz}$, with a peak-to-peak displacement 


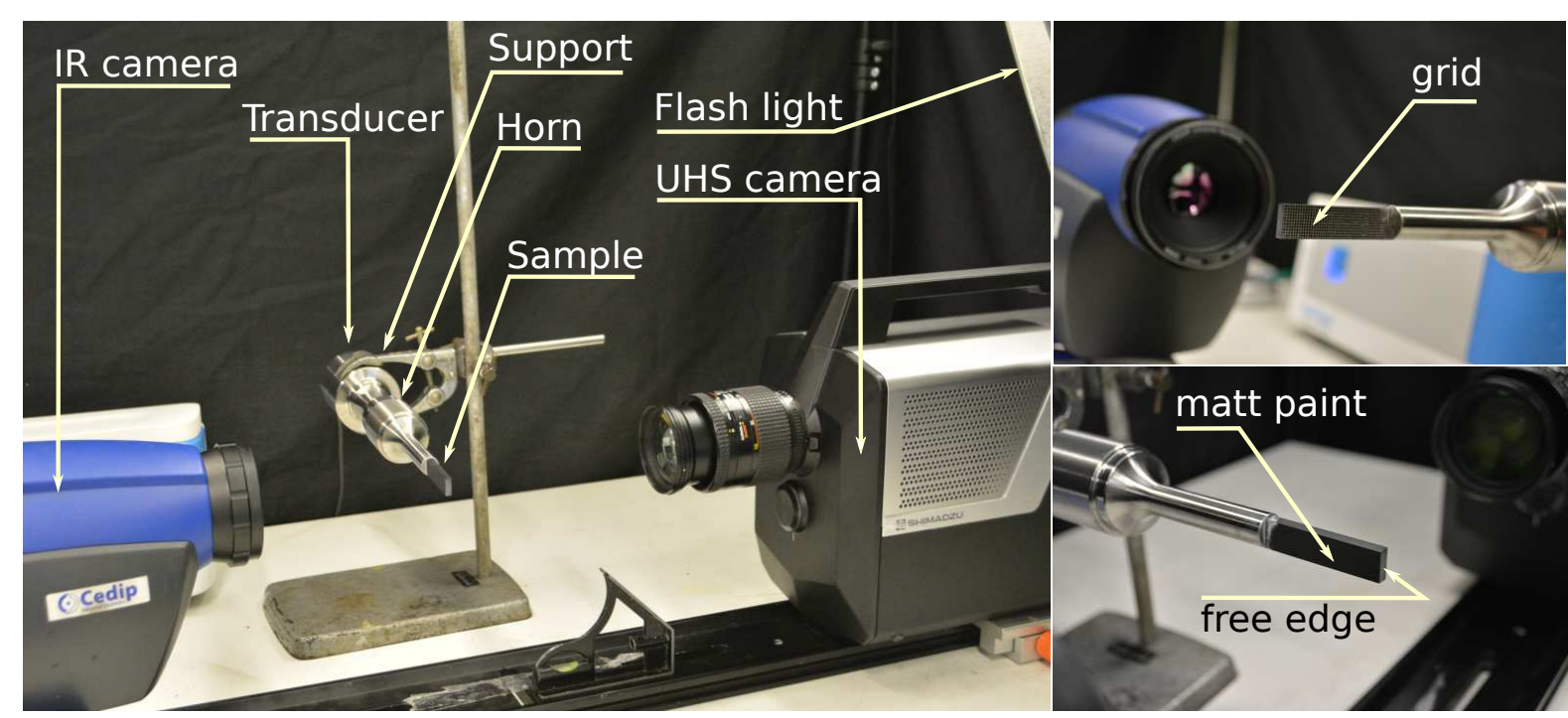

FIGURE 1 - Image-Based DMTA experimental setup

amplitude of about $60 \mu m$ - (2) An Infra-Red camera which allows reconstructing surface temperature fields. The IR camera has a resolution of $320 \times 256$ pixels and is used at $50 \mathrm{fps}$ - (3) An Ultra-High speed camera which allows capturing images of the deforming sample to obtain space and time resolved displacement and acceleration fields. The UHS camera has a resolution of $400 \times 250$ pixels and 128 frames are recorded at $500 \mathrm{kfps}$. (4) Finally, a regular and adhesive grid is used to extracts the in-plane displacement fields from the phase-shifting algorithm [5]. The test consists basically in a set of successive short ultrasonic runs $(800 \mathrm{~ms})$. Within each run a $256 \mu \mathrm{s}$ Ultra-High Speed image sequence of the deforming sample is grabbed. In parallel, the IR data are continuously recorded until the sample melt after a certain number of run. In addition, the initial sample temperature can be controlled to extend the total temperature range seen by the sample during the test. To estimate the measurement uncertainty, sets of static images under true experimental conditions are taken and allow estimating that the measurement noise is at least an order of magnitude below the signal during loading conditions. For this experiment, the tested sample is a $55 \times 12 \times 4 \mathrm{~mm}$ flat and transparent PMMA (Poly-Methyl-MethAcrylate) sample simply glued on the tip of the horn (see figure 1). The dimensions of the sample, especially the length, have been chosen to ensure that the material reach its first longitudinal deformation mode at $20 \mathrm{kHz}$. Finally, as seen in figure 1, the sample is covered with a black matt paint on one face, to achieve efficient IR measurements and, on the other face, with the regular grid described above.

\section{Results and discussions}

Figure 2 presents first a characteristic displacement and strain profile along the sample length. The displacement varies from -20 to $+20 \mu m$ at both sample extremities while the strain reaches it maximum value within the sample centre, here $1600 \mu$ def, and oscillates cycle after cycle. Strain can be differentiate once in time to obtain strain-rate, while displacement can be differentiate twice in time to obtain acceleration and then stress.

Figure 3 (left and centre) presents some stress-strain curves obtained during two different ultrasonic runs. At these stages the temperature reaches $30^{\circ} \mathrm{C}$ and $105^{\circ} \mathrm{C}$ respectively within the sample centre. One can 


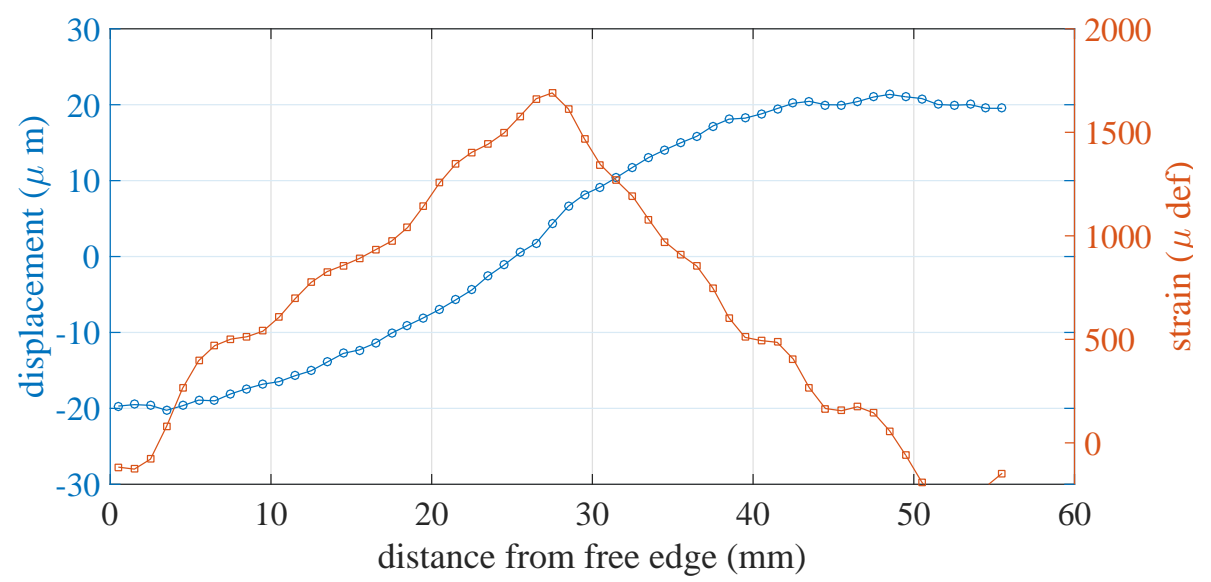

FiguRE 2 - Example of displacement and strain profiles along sample length (from free to fixed edge).
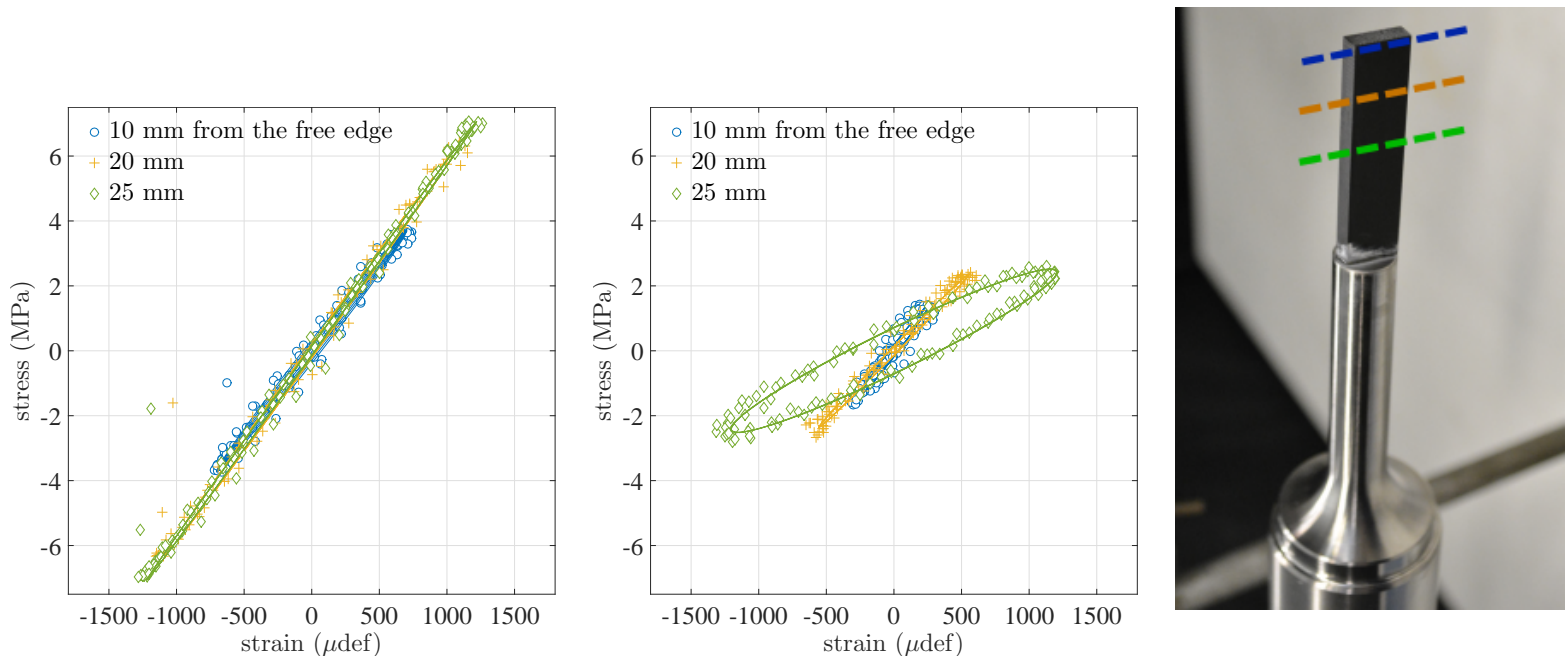

FIGURE 3 - Stress-strain curves for 3 different sample sections, from free edge to sample centre (see figure on the right), and for two different ultrasonic runs.

clearly see, a variation of the storage modulus as well as a variation of the damping along the sample length. Such variation is the result of two main phenomena. A $1^{\text {st }}$ order one, the material temperature sensitivity, which leads to a drop of the storage modulus and to the appearance of hysteresis loops when one approaches the central section. A $2^{\text {nd }}$ order one - a material strain-rate sensitivity, which should mitigate the storage modulus drop by making the material stiffer within the central region [6].

To go further and make a clear partition between both phenomena, it is then necessary to build a 3D representation of the material behaviour such as, $\mathrm{E}=f(\dot{\varepsilon}, T)$, i.e. combining all the experimental data to evidence how the storage modulus and the material damping evolves as a function of the two main variables identified here, i.e. the strain-rate and the temperature. To achieve this, both stress and strain, for each material section and ultrasonic runs, are temporally fitted by a sine function as follow :

$$
\begin{aligned}
& \varepsilon_{f}(x, t)=\alpha_{0} \sin \left(2 \pi f t+\phi_{0}\right) \\
& \sigma_{f}(x, t)=\alpha_{1} \sin \left(2 \pi f t+\phi_{1}\right)
\end{aligned}
$$


where $f$ is the loading frequency, $t$ is the time, $x$ is the axial position and $\alpha_{i}$ and $\phi_{i}$ are the amplitudes and phases of strain and stress for $i=0$ and $i=1$ respectively. From this description, the storage modulus can be simply obtained from the ratio $\frac{\alpha_{1}}{\alpha_{0}} \cos (\delta)$, with $\delta=\phi_{1}-\phi_{0}$. Notice that the material damping, $\tan (\delta)$, can also be simply identified from the temporal phase shift between the stress and the strain, i.e. $\tan (\delta)(s, t)=\tan \left(\phi_{0}-\phi_{1}\right)$.
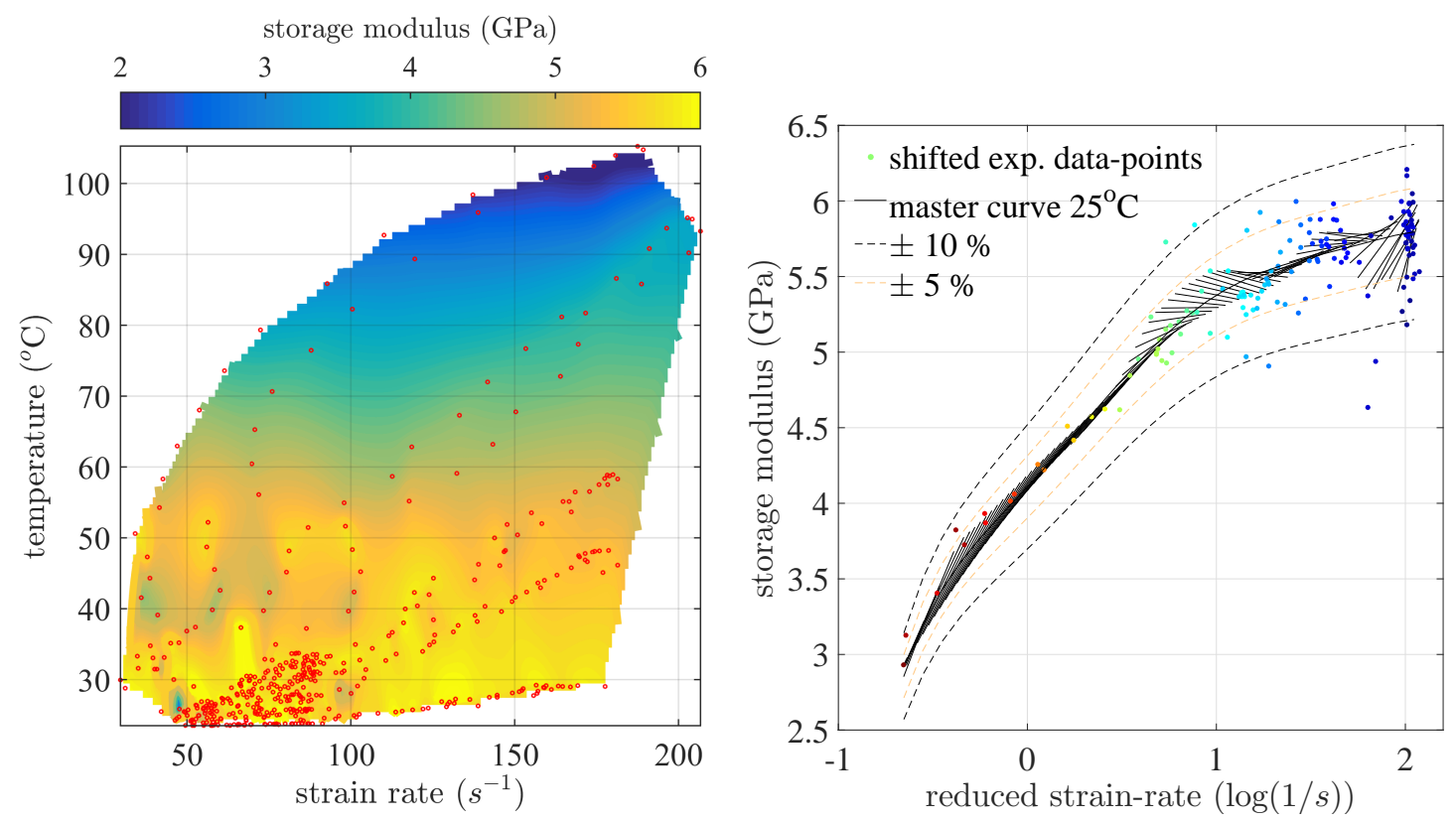

FiguRE 4 - Identified PMMA properties from 5 ultrsasonic runs on a single sample. (left) Storage modulus variation as a function of the $\dot{\varepsilon}$ and $T$ (Dotted points are experimental data) and (right) the associated reconstructed master curve at $25{ }^{\circ} \mathrm{C}$. The colour gradient from dark-blue (cold) to red (hot) shows the relative temperature of each data-point.

The figure 4 focuses on the material storage modulus. Dotted points within figures 4 are the experimental data points. Each of them corresponds to the identification obtained from a specific sample section at a specific ultrasonic run. The field (see Fig. 4 - left) is then produced interpolating the experimental data. This is therefore the gathering of spatio-temporal data coming from a unique sample. The following map evidences and allow quantifying the drop of the storage modulus as the sample temperature increases but also evidences a slight rising of the modulus when the strain-rate grows. Such a strain-rate sensitivity is confirmed when reconstructing the material master curve at $25{ }^{\circ} \mathrm{C}$ (see Fig. 4 - right) based on the time-temperature superposition principle. The storage modulus varies from less then $3 \mathrm{GPa}$ to more than 5.5 GPa when the reduced strain-rate range from 0 to $180 \mathrm{~s}^{-1}$ respectively. From this curve a material activation energy of $88 \mathrm{~kJ} \cdot \mathrm{mol}^{-1}$ has also been identified. In addition, the data suggests that cooling the sample only down to $0{ }^{\circ} \mathrm{C}$ would allow us to reach a reduced strain-rate in the order of $10^{3}$ $\mathrm{s}^{-1}$ i.e. achieving a strain-rate range of 3 decades. 


\section{Conclusions}

The present work demonstrates the feasibility of a multi-parametric identification, at intermediate strainrate, on a single sample and falls within an effort to invent new high-strain test methodologies based on full-field imaging and inverse identification, to both overcome the limits of standard experimental strategies and take advantage of the deformation heterogeneities to achieve a full-characterization of a material from a "one-shot" test.

\section{Références}

[1] F Pierron, H Zhu, and C Siviour. Beyond hopkinson's bar. Philosophical Transactions of the Royal Society of London A : Mathematical, Physical and Engineering Sciences, 372(2023) :20130195, 2014.

[2] D Wang, M Lucas, and KE Tanner. Characterising the strain and temperature fields in a surrogate bone material subject to power ultrasonic excitation. Strain, 49(5) :409-419, 2013.

[3] R Seghir and F Pierron. Viscoelastic properties identification through innovative image-based dmta strategy. In International Digital Imaging Correlation Society, pages 207-209. Springer, 2017.

[4] F Pierron and R Seghir. Ultrasonic test for high rate material property imaging. In Advancement of Optical Methods in Experimental Mechanics, Volume 3, pages 173-176. Springer, 2017.

[5] Michel Grediac, Frédéric Sur, and Benoit Blaysat. The grid method for in-plane displacement and strain measurement : A review and analysis. Strain, 52(3) :205-243, 2016.

[6] Zhouhua Li and John Lambros. Strain rate effects on the thermomechanical behavior of polymers. International Journal of Solids and Structures, 38(20) :3549-3562, 2001. 